\title{
High-efficiency transfection of mammalian neurons via nucleofection
}

\author{
Manuel Zeitelhofer, John P Vessey, Yunli Xie, Fabian Tübing, Sabine Thomas, Michael Kiebler \& Ralf Dahm
}

Division of Neuronal Cell Biology, Center for Brain Research, Medical University of Vienna, A-1090 Vienna, Austria. Correspondence should be addressed to R.D. (ralf.dahm@meduniwien.ac.at).

Published online 28 June 2007; doi:10.1038/nprot.2007.226

Transfection of foreign DNA is widely used to study gene function. However, despite the development of numerous methods, the transfer of DNA into postmitotic cells, such as neurons, remains unsatisfactory with regard to either transfection efficiency or cytotoxicity. Nucleofection overcomes these limitations. Direct electroporation of expression plasmids or oligonucleotides into the nucleus ensures both good cell viability and consistently high transfection rates. This allows biochemical analyses of transfected neurons, for example, western blot analyses of protein levels after RNA interference (RNAi) knockdown or microRNA transfection. We provide comprehensive protocols for performing nucleofection with high efficiency on primary neurons. The focus is on the recently developed 96-well shuttle system, which allows the simultaneous testing of up to 96 different plasmids or experimental conditions. Using this system, reproducible high-throughput expression of various transgenes is now feasible on primary neurons, for example large-scale RNAi analyses to downregulate gene expression. The protocol typically takes between 2 and $3 \mathrm{~h}$.

\section{INTRODUCTION}

The transfection of foreign nucleic acids into cultured cells is used widely to study gene function. It is a rapid and efficient way to introduce transgenes or oligonucleotides into cells and study their effects or the behavior of the encoded proteins in the context of a living cell. Fluorescently tagged proteins, for instance, have been instrumental in elucidating the localization and movement of proteins inside living cells ${ }^{1-3}$. In addition, transfected constructs can serve as reporters for a variety of cellular processes, such as local RNA translation ${ }^{4}$ and turnover, or intracellular $\mathrm{Ca}^{2+}$ concentrations, particularly in neurons ${ }^{5}$. Moreover, transfection of tagged proteins can serve as bait for subsequent immunoprecipitation or pull-down experiments. Finally, the transfection of short hairpin RNA (shRNA) constructs ${ }^{6}$, and more recently microRNAs ${ }^{7}$, is widely employed to knock down the expression of specific genes.

Given this wide range of possible applications of DNA transfer into cells, it comes as no surprise that a large number of transfection protocols have been established. They include the transfection with $\mathrm{Ca}^{2+}$-phosphate/DNA co-precipitates, lipid-based transfection protocols (lipofection), electroporation, microinjection, biolistics, as well as adeno-, lenti- and retrovirus-based methods (reviewed in refs. 3,8$)$. However, despite the development and modification of a variety of gene transfer methods, introducing DNA into postmitotic cells, such as neurons, remains unsatisfactory with regard to either cytotoxicity or transfection efficiency ${ }^{9,10}$.

Generally, transfection methods based on $\mathrm{Ca}^{2+}$-phosphate/DNA co-precipitates result in transfection efficiencies that are sufficient for approaches that analyze individual cells, for example, in microscopy experiments. Similarly, the transfection efficiencies of lipid-based protocols are adequate for such applications. For experiments requiring very high transfection rates, however, these techniques are not suitable. Moreover, lipofection can interfere with the attachment of cells to their substrate, and particularly in neurons, can lead to the detachment of dendrites and axons. Although every transfection method represents a stress for the cells and can thus lead to reduced viability, this is a particular concern with microinjection and biolistics approaches where the cells can sustain significant physical damage. Additionally, microinjection of individual cells is a very laborious procedure and cannot be used to transfect cells on a large scale. In contrast to the above-mentioned techniques, virus-based transfection methods can reach very high transfection efficiencies. They have, however, the drawback that viral particle preparation is time consuming. Moreover, working with viruses requires additional safety precautions, such as dedicated S2 laboratory space. For an overview of the advantages and drawbacks of the different transfection techniques employed with neurons, refer to Table 1 .

Low-to-medium transfection efficiencies are generally sufficient when working with proliferating cells, which can be expanded from selected transfected cells, or when low transfection efficiencies are sufficient. They pose a problem, however, for postmitotic cells when large numbers of transfected cells are required or entire populations of cells are pooled and subsequently analyzed as one sample. Large numbers of cells may, for instance, be required for the purification of protein complexes in immunoprecipitation or pull-down experiments. Pooling of cells is important, for example, when the efficiency of a small interfering RNA (siRNA) knockdown or the effects of microRNA treatments are to be assessed. Changes in the expression levels of proteins, for example, the reduction of siRNA targets, are difficult to assess on the single-cell level, as immunocytochemical stainings are notoriously difficult to quantify (only a complete absence of staining can be easily interpreted) and large numbers of cells would have to be analyzed to obtain representative average expression levels. Moreover, it is difficult to define and analyze markers to which changes in the level of the targeted protein can be correlated. This also holds true with regard to the potentially large number of proteins whose expression may be affected by microRNA treatments. Extracting total protein from transfected cells followed by quantitative western blot analyses is a straightforward way of determining the levels of numerous proteins and correlating them to a set of control proteins. Since material from at least 500,000 to 1 million cells has to be pooled, however, the accuracy of the results obtained crucially depends on high transfection efficiencies. 
TABLE 1 | Advantages and disadvantages of different transfection techniques employed with neurons.

\begin{tabular}{ll}
\hline Transfection technique & Benefits \\
\hline $\mathrm{Ca}^{2+}$-phosphate co-precipitate & (a) Cost-effective \\
& (b) Comparatively simple to optimize for a variety \\
& of plasmids \\
(c) Neurons tolerate transfections well with \\
comparatively little cell toxicity
\end{tabular}

Lipid-based methods

(lipofection)

(a) Simple transfection method with many companies supplying standardized kits

(b) High transfection efficiencies for non-neuronal cell lines

(a) High transfection efficiency

(b) Low cell toxicity

Lenti- and retroviral-based transfections

Biolistics

Microinjection

Electroporation

Nucleofection (a) Medium-to-high transfection rates

(a) Useful for transfecting neurons in organotypic slice cultures that are difficult or impossible to transfect with other techniques

(a) Can directly inject RNA, rather than DNA plasmids requiring synthesis of mRNA before protein can be made

(b) Injection of directly labeled RNA or oligonucleotides possible

(a) Very high transfection efficiencies attainable

(b) Low cell toxicity due to finely regulated sequences of voltage pulses and cell type-specific nucleofection solutions

(c) Transfection of DNA often leads to nuclear localization of the exogenous plasmids, leading to better expression

(d) Reproducible and simple to use, once the procedure has been optimized

\section{Drawbacks}

(a) Low transfection efficiencies, typically ranging between $1 \%$ and $10 \%$ (although this can be a benefit if analyzing single neurons)

(b) Can be difficult to yield reproducible results

(a) Toxic to neurons

(b) Cells that do survive the transfection procedure often suffer from drastic morphological changes (dendrites and axons often detach from the culture surface)

(a) Preparation of the viral particles for transfection is time consuming

(b) Working with viruses requires additional safety precautions that are expensive and not always feasible for smaller laboratories

(a) Biolistics is extremely stressful for cells since a particle roughly one-tenth the size of a neuronal cell body is shot into the cell

(b) Relatively expensive equipment and reagents

(a) Very low transfection rate, limited by the type of neuron (larger neurons are easier to inject) and the ability of the experimenter to inject neurons

(b) Cell survival is extremely poor, further limiting the transfection rate

(c) Relatively expensive equipment

(a) Can only transfect freshly isolated neurons that have yet to produce neurites

(b) Transfection efficiencies limited by premature voltage pulse termination

(c) Can be toxic to cells due to prolonged voltage pulses

(d) Relatively expensive equipment and reagents

(a) Can transfect only freshly isolated neurons that have yet to produce neurites

(b) Relatively expensive equipment and reagents

\section{Strengths of the nucleofection technique}

The nucleofection technique ${ }^{11}$ overcomes many of the limitations of the above-mentioned methods. It ensures both good cell viability and consistently high transfection rates of up to $95 \%$. As a consequence, in many cases, nucleofection is the method of choice to achieve very high levels of transfection in cultured primary neurons. It allows, for example, biochemical analyses of transfected primary neurons, in the form of western blot analyses of protein levels after RNAi knockdown ${ }^{12,13}$ or microRNA transfection. An additional advantage of the nucleofection technique is that 
compared with, for example, $\mathrm{Ca}^{2+}$-phosphate/DNA co-precipitatebased methods, it requires minimal optimization. Finally, the transfection efficiencies obtained by nucleofection tend to be more reproducible than those attained with other methods.

The nucleofection technique is based on electroporation. In electroporation, the application of voltage pulses temporarily alters the physical properties of the plasma membrane and thus allows extracellular material, including plasmids from the surrounding medium, to enter the cells. In contrast to conventional electroporation, nucleofection combines specific electrical parameters with cell type-specific reagents to ensure a good viability of cells. Moreover, it facilitates the transfer of transfected constructs directly into the nucleus. This is of particular importance when postmitotic cells are to be made accessible for efficient gene transfer ${ }^{14,15}$.

In nucleofection, very high field strengths are used to aid DNA or other biologically active molecules enter the nucleus independently of cell division. The cell type-specific high-voltage pulses generated by the nucleofector device facilitate penetration of foreign molecules into the nucleus, possibly by transiently creating holes in the nuclear envelope or rendering the nuclear pores more permeable to large molecules, thus enabling very efficient transport of biologically active molecules into the nucleus. For details on the nucleofection procedure and the nucleofector device, see ref. 16.

An additional problem with conventional electroporation techniques is that long-lasting pulses lead to the generation of cytotoxic anions. This can result in high rates of cell death. The short, highvoltage pulses used in nucleofection diminish this problem. Further, the buffers used in nucleofection have a high buffer capacity and a high ionic strength. They are therefore optimized to achieve high transfection efficiencies with a low cell mortality rate and are especially suitable for electrotransfection of quiescent or weakly dividing cells. For details on nucleofection buffer, see ref. 17 .

This combination of short high-voltage pulses and optimized buffers minimizes damage to the cellular membranes while ensuring high rates of transfection and cell survival, making nucleofection a more efficient transfection method than conventional electroporation. For comparisons between nucleofection and conventional electroporation, see refs. 18,19 .

The first-generation nucleofection technology, the nucleofector device, used a single cuvette into which cells were loaded for nucleofection. Recently, a new nucleofection system, the 96-well shuttle, has been developed, which offers several unique features over the first-generation device (see also ref. 20). The new system uses 96-well plates and thus allows the simultaneous testing of up to 96 different plasmids or conditions. For the first time, reproducible high-throughput expression of various transgenes is now feasible in primary neurons. For example, the system allows large-scale parallel analyses, such as RNAi library screening to downregulate gene expression on a systematic level. Similarly, the effects of large numbers of microRNAs could be tested or ELISA screening after RNAi knockdown could be performed. The possibility to simultaneously test up to 96 conditions, such as different solutions/media or nucleofection programs, eliminates variations that can hinder comparisons between experiments performed on separate neuronal preparations. In addition, the 96-well shuttle nucleofector requires an order of magnitude fewer cells than are necessary with the firstgeneration device. This is particularly important when cell types that are of low abundance or time consuming to isolate are used. It should, however, be noted that the transfection efficiencies achieved with the 96-well shuttle system tend to be somewhat lower than those of the nucleofector device. As a consequence, experiments requiring very high transfection rates may be more efficiently performed with the latter.

\section{Limitations of the nucleofection technique}

A limitation of current nucleofection protocols is that they are more expensive compared to $\mathrm{Ca}^{2+}$-phosphate/DNA- or lipofection-based transfection methods regarding the equipment and solutions needed. The biggest drawback of using nucleofection when working with primary neurons, however, is that the procedure can be applied only to cells in suspension. For primary neurons, this means that the cells have to be transfected immediately after isolation from the animal. This may limit experiments on mature neurons. In culture, neurons require at least 7 days to differentiate into mature neurons with developed axons, a dendritic tree and functional synapses. A prolonged overexpression of transgenes, however, may interfere with neuronal differentiation, precluding the analysis of late phenotypes in mature neurons and often results in artifacts or even cell death ${ }^{3}$. Moreover, it may be desirable to assess the effect of a knockdown only in mature neurons, without affecting gene expression during differentiation. In these cases, plasmids with inducible promoters may have to be used. Another issue that arises with nucleofection is reproducibility of transfection efficiency between different plasmids. This problem, however, is not unique to nucleofection and can cause difficulties with almost all transfection techniques.

\section{MATERIALS}

\section{REAGENTS}

- Pregnant mice or rats carrying embryonic day (E)15.5 and E17 embryos, respectively ! CAUTION All experiments involving live rodents must conform to National and Institutional regulations.

-65\% nitric acid (Sigma, 17078-1L) ! CAUTION Caustic: destroys skin upon contact.

- Paraffin pellets (Merck, 1.07158)

- Poly-L-lysine hydrobromide powder (Sigma, \#P2636)

- Borate buffer (see REAGENT SETUP) I CAUTION Harmful. Sodium borate

can cause irritation to skin, eyes and respiratory system; targets organs; harmful to the unborn child.

- Hanks' balanced salt solution (HBSS; see REAGENT SETUP)

- Phosphate-buffered saline (PBS; see REAGENT SETUP)

- Tris-EDTA buffer (TE buffer; see REAGENT SETUP)

- Trypsin-EDTA solution (see REAGENT SETUP)
- Cell culture media (see REAGENT SETUP)

- Freezing medium (VWR Cryostor, CS10 80093-724)

-1- $\beta$-D-arabinofuranosylcytosine (Ara-C; Calbiochem, 14794-4) ! CAUTION Toxic. Harmful if inhaled, absorbed through skin or swallowed; may cause birth defects.

- Barrycidal 36 (Biohit Deutschland, 5ZSF1000)

-70\% (vol/vol) ethanol

EQUIPMENT

- Stereomicroscope with brightfield transmission illumination achieving magnifications of up to $\times 200$ (combined ocular-objective magnification)

- Vannas spring scissors (FST 15001-08)

- Straight forceps (Dumont \#5, FST 11252-20)

- Sterile $10 \mathrm{~cm}$ cell culture dishes (Greiner, 663102)

- Sterile $3.5 \mathrm{~cm}$ cell culture dishes (Greiner, 627102)

- Sterile Pasteur pipettes (normal and fire-polished; Brand, 747720) 


\section{BOX 1 | PREPARATION OF POLY-L-LYSINE-COATED COVERSLIPS AND TISSUE CULTURE DISHES TIMING 5 DAYS}

Depending on the nature of the experiment, neurons can be plated either on poly-L-lysine-coated glass coverslips or cell culture plastic dishes. The following protocol will allow for the simultaneous preparation of both.

\section{Coating of coverslips}

1. Place coverslips in porcelain staining racks and submerge in $65 \%$ nitric acid for $18-36 \mathrm{~h}$. Wash coverslips in sterile, distilled and deionized water three times for 5 min followed by three times for $20 \mathrm{~min}$.

2. Place the porcelain racks with the coverslips in a glass container and dry in an oven at $70{ }^{\circ} \mathrm{C}$ (typically it takes $1 \mathrm{~h}$ ).

PAUSE POINT These clean coverslips can be stored in a dry, sterile environment for up to 2 weeks.

3. Cover the glass container holding the porcelain racks with the coverslips with aluminum foil and sterilize in an oven with dry heat at $220{ }^{\circ} \mathrm{C}$ for $7 \mathrm{~h}$.

$\triangle$ CRITICAL STEP Do not autoclave the coverslips, as this will render them unsuitable for neuronal culturing.

4. In a laminar flow hood, place six coverslips in a $6-\mathrm{cm}$ cell culture grade plastic dish, ensuring that they do not touch each other or the edge of the dish.

5. Melt paraffin pellets in a 50-ml glass bottle by heating to approximately $100{ }^{\circ} \mathrm{C}$ on a heated plate. Suck up the molten paraffin into a sterile glass Pasteur pipette and place three dots of paraffin (should be approximately $1 \mathrm{~mm}$ in diameter and approximately $0.5 \mathrm{~mm}$ in height) near the outer edge of each coverslip to form a triangle. These paraffin dots will prevent the cultured neurons from contacting the glial culture when placed upside-down onto a glia feeder layer.

$\triangle$ CRITICAL STEP For dotting, do not use paraffin of a temperature above $70{ }^{\circ} \mathrm{C}$, otherwise it will not be viscous enough and will run over the coverslip. Too little heat and the paraffin will not seal with the glass.

$\triangle$ CRITICAL STEP The size of the dots is important to ensure proper spacing between the glial feeder layer and the neurons. If the dots are too flat, the neurons might touch the glia.

6. Dissolve poly-L-lysine hydrobromide powder in borate buffer to $1 \mathrm{mg} \mathrm{ml}^{-1}$ and sterilize by passing through a $0.22-\mu \mathrm{m}$ pore size filter. Place approximately $100 \mu \mathrm{l}$ of the poly-L-lysine solution on each coverslip and store the culture dishes in a tissue culture incubator at $36.5{ }^{\circ} \mathrm{C}$ with a humidified, $5 \% \mathrm{CO}_{2}$ atmosphere for $24 \mathrm{~h}$.

7. Aspirate the poly-L-lysine solution off the coverslips. (Note: the poly-L-lysine solution aspirated off the coverslips can be saved for the coating of the 6 -cm plastic tissue culture dishes; see below.) Rinse each dish containing the coverslips with water, once for 5 min and a second time for 2 h. During the second wash, rearrange the coverslips so that each dish now contains eight non-overlapping coverslips. This optimizes the area on which the dissociated neurons can settle when they are transferred into the dish. Following the final wash, fill each dish with $5 \mathrm{~mL}$ of DMEM-HS and store in an incubator for at least $24 \mathrm{~h}$ and up to 2 weeks.

8. Remove the DMEM-HS from the dish and replace with NMEM-B27 and leave to equilibrate in a tissue culture incubator (humidified, $5 \% \mathrm{CO}_{2}$ ) for at least $1 \mathrm{~h}$ before seeding neurons onto the coverslips.

Coating of cell culture dishes or multi-well plates

1. Dissolve poly-L-lysine hydrobromide powder in borate buffer to $0.1 \mathrm{mg} \mathrm{ml}^{-1}$ and sterilize by passing through a $0.22-\mu \mathrm{m}$ pore size filter (Note: the poly-L-lysine solution used to coat the dishes/wells can be diluted (with $\mathrm{dH}_{2} \mathrm{O}$ ) from the solution recovered from the coating of the coverslips; see Step 7 above.) Place a sufficient volume of this solution into the desired dish or well to cover the bottom surface, for example approximately $5 \mathrm{ml}$ into a 6 -cm plastic dish, and transfer to a tissue culture incubator for $24 \mathrm{~h}$.

2. Following the coating period, rinse each dish or well with $\mathrm{dH}_{2} \mathrm{O}$ once for $5 \mathrm{~min}$ and a second time for $2 \mathrm{~h}$. After the second wash, fill each dish with DMEM-HS, for example $5 \mathrm{ml}$ in case of a 6 -cm culture dish, and return to the incubator for at least $12 \mathrm{~h}$ and up to 2 weeks.

3. Remove the DMEM-HS from the dish and replace with NMEM-B27 and leave to equilibrate in a tissue culture incubator (humidified, $5 \% \mathrm{CO}_{2}$ ) for at least $1 \mathrm{~h}$ before seeding neurons onto the dishes or wells.

Note that coverslips, culture dishes or multiwell plates coated according to the above protocols can also be used to culture untransfected neurons or neurons transfected with other protocols.

- Cell culture flasks (Nunc, 153732)

- Centrifuge with rotor accommodating $15 \mathrm{ml}$ conical tubes

- Glass coverslips (Marienfeld, 0111550), $15 \mathrm{~mm}$ diameter, coated with poly-L-lysine or otherwise as required (for a poly-L-lysine coating protocol, see Box 1)

- Porcelain staining racks for coverslips (Thomas Scientific, 8542E40)

- Oven to dry-heat-sterilize

-Sterile $6 \mathrm{~cm}$ cell culture grade plastic dish (Nunc, 150288)

- Heated plate

$\cdot 0.22 \mu \mathrm{m}$ pore size filters (Millipore, SLGS025NB)

-Sterile plasticware: $15 \mathrm{ml}$ conical tubes (Greiner, 188271), $1.5 \mathrm{ml}$ Eppendorf

tubes (Eppendorf, 30120086), tips for single channel pipettes

- Laminar flow hood (class II preferred)

- Tissue culture incubator at $37{ }^{\circ} \mathrm{C}$ with humidified, $5 \% \mathrm{CO}_{2}$ atmosphere

- Water bath at $37^{\circ} \mathrm{C}$

\footnotetext{
- Hemocytometer for counting cells (Brand, 717805)

- Clean single channel pipettes (2, 20, 200 and 1,000 $\mu$ l capacity)

- Nucleofector device (Amaxa, AAD-1001)

- Rat neuron nucleofector kit (Amaxa, VPG-1003) or mouse neuron nucleofector kit (Amaxa, VPG-1001) containing cuvettes for the nucleofection reaction, plastic pipettes, pmaxGFP control expression plasmid, nucleofector solution and nucleofector supplement; needed only if using the nucleofector device

-96-well shuttle nucleofector (Amaxa, AAM-1001).

- Rat neuron 96-well nucleofector kit (Amaxa, VHPG-1003) containing $2 \times 8$ nucleofection modules, pmaxGFP control expression plasmid, nucleofector solution and nucleofector supplement; needed only if using the 96-well shuttle

- Multichannel pipette with eight channels and 10-100 $\mu$ capacity

(Eppendorf, 3144000.131); needed only if using the 96-well shuttle
} 
• epT.I.P.S. pipette tips (Eppendorf, 0030073.266) for multichannel pipette; needed only if using the 96-well shuttle

-Sterile conventional 96-well plates coated with poly-L-lysine; needed only if using the 96-well shuttle

- PCR eight-tube strips (Eppendorf, 30124359); needed only if using the 96-well shuttle

\section{REAGENT SETUP}

Borate buffer $50 \mathrm{mM}$ boric acid (Sigma, B6768) and $12.5 \mathrm{mM}$ sodium borate (Sigma, B9876) in $\mathrm{ddH}_{2} \mathrm{O}$; adjust $\mathrm{pH}$ to 8.5 .

HBSS $20 \mathrm{mM}$ HEPES (Sigma, H3375), $2 \mathrm{mM} \mathrm{CaCl}_{2}$ (Merck, 102382), $5.4 \mathrm{mM}$ $\mathrm{KCl}$ (Riedel Haën, 31248), 1 mM MgCl 2 (Fluka, 63063), $136 \mathrm{mM} \mathrm{NaCl}$ (Riedel Haën, 31434), $1 \mathrm{mM} \mathrm{Na}_{2} \mathrm{HPO}_{4}$ (Riedel Haën, 04272) and $5.6 \mathrm{mM}$ glucose (Merck, 1.08337.1000) in $\mathrm{ddH}_{2} \mathrm{O}$; adjust $\mathrm{pH}$ to 7.3.

PBS $137 \mathrm{mM} \mathrm{NaCl}, 6.5 \mathrm{mM} \mathrm{Na}_{2} \mathrm{HPO}_{4}, 2.7 \mathrm{mM} \mathrm{KCl}$ and $1.5 \mathrm{mM} \mathrm{KH}_{2} \mathrm{PO}_{4}$ in $\mathrm{ddH}_{2} \mathrm{O}$; adjust $\mathrm{pH}$ to 7.1. Ready-to-use mixture without $\mathrm{Ca}^{2+}$ and $\mathrm{Mg}^{2+}$

(Biochrom, L182-10).

TE buffer $10 \mathrm{mM}$ Tris- $\mathrm{HCl}$ (Sigma, T1503-5KG) and $1 \mathrm{mM}$ EDTA (Sigma, E5134-1KG) in $\mathrm{ddH}_{2} \mathrm{O}$; adjust $\mathrm{pH}$ to 7.5 .

Trypsin-EDTA solution Make up to contain $1 \times$ trypsin/EDTA from a $10 \times$ stock containing $0.5 \%$ (wt/vol) trypsin and $0.2 \%$ (wt/vol) EDTA (Biochrom, L2153), 0.1\% (wt/vol) HEPES (Sigma, H3375-5KG) and $100 \mathrm{U} \mathrm{ml}^{-1}$ penicillin and $10 \mu \mathrm{g} \mathrm{m}^{-1}$ streptomycin from a $100 \times$ stock solution (Sigma, P0781) in $1 \times$ PBS (Biochrom, L182-10).

B27-supplemented NMEM (NMEM-B27) $1 \times$ MEM (modified Eagle's medium) from a 10× MEM stock (Invitrogen, 21430-020), $26 \mathrm{mM}$

$\mathrm{NaHCO}_{3}$ (Riedel Haën, 31437), 1 mM sodium pyruvate (Sigma, P2256-5G), $200 \mathrm{mM}$ L-glutamine, stable (Promocell, C42215), $33 \mathrm{mM}$ D-glucose (Merck, 1.08337.1000) and 2\% (vol/vol) B27 supplement (Invitrogen, 17504044) dissolved in $\mathrm{ddH}_{2} \mathrm{O} ; \mathrm{pH}$ adjusts automatically to 7.4 via the $\mathrm{CO}_{2}$ concentration $(5 \%)$ in the incubator.

Dulbecco's modified Eagle's medium-horse serum 1× DMEM (Dulbecco's modified Eagle's medium) containing 4,500 $\mathrm{mg} \mathrm{liter}^{-1}$ glucose and GlutaMAX-I (Invitrogen, 61965-026), 10\% (vol/vol) horse serum (HS) (Invitrogen, 16050122), $1 \mathrm{mM}$ sodium pyruvate (Sigma, P2256-5G) and $200 \mathrm{mM}$ L-glutamine (Promocell, C42215).

Postnatal day 0 culture medium $1 \times$ DMEM containing $4,500 \mathrm{mg} \mathrm{liter}{ }^{-1}$ glucose and GlutaMAX-I (Invitrogen, 61965-026), 10\% (vol/vol) HS (Invitrogen, $16050122), 2 \%$ (vol/vol) B27 supplement (Invitrogen, 17504044), 2.5\% (vol/vol) insulin solution (human recombinant zinc solution) (Invitrogen, 12585014), 2 mM GlutaMAX-I (Invitrogen, 35050-038), $5 \mu \mathrm{M}$ Ara-C (Invitrogen, 14794-4) and $100 \mathrm{mg} \mathrm{liter}^{-1}$ transferrin (bovine holotransferrin) (Invitrogen, 11107018).

\section{PROCEDURE}

\section{Preparation of glial support cultures, optional TIMING $\sim \mathbf{1 4}$ days}

1) If, after nucleofection, the experiment requires plating the transfected neurons on coverslips and subsequent culture for $>3$ days, it is recommended to establish a glial support culture. To establish a glial support culture, begin approximately 12 days before the nucleofection. Follow the procedure detailed in Box 2 to isolate the glial cells before proceeding with the rest of the protocol outlined below.

\section{Preparation of dissociated E17 hippocampal neurons $\bigcirc$ TIMING $\sim 1-2 \mathrm{~h}$ \\ 2| Warm HBSS and trypsin-EDTA to $37^{\circ} \mathrm{C}$ in a water bath.}

3| Anesthetize a timed pregnant rat (E17) or mouse (E15.5) and kill the animal using an approved method.

$\triangle$ CRITICAL STEP The entire experiment should be completed within $2 \mathrm{~h}$ of killing the animal. Survival rates of isolated neurons will decrease substantially after this time.

4| In a laminar flow hood, sterilize the abdomen with Barrycidal or $70 \%$ ethanol. Using large forceps and scissors, make an incision on the midline through the skin starting at the pelvis and ending at the thorax, ensuring not to cut through the underlying muscle. Separate the skin from the muscle and sterilize the abdomen with $70 \%$ ethanol. Cut through the abdomen and open a large area to expose the uterus.

5| With the same forceps, take hold of the uterus between two embryos, lift and cut the uterine horn. Dissect out the entire uterus with the embryos and place in a sterile $10 \mathrm{~cm}$ plastic tissue culture dish.

6| Carefully remove the embryos from the uterus. For this, cut along the placenta of each embryonic sack and allow the embryo to drop out. Cut the umbilical cord and place the embryo into a separate $10 \mathrm{~cm}$ plastic dish filled with prewarmed HBSS.

7| Using smaller, sterile forceps, place an embryo into a third, sterile $10 \mathrm{~cm}$ plastic dish without HBSS and decapitate with fine scissors. Cut along the middle vein through the skin and skull and gently remove the skull to reveal the brain.

8| Using a small spatula, remove the whole brain and place it into a small, $3 \mathrm{~cm}$ sterile tissue culture dish filled with prewarmed $\left(37^{\circ} \mathrm{C}\right) \mathrm{HBSS}$.

$\triangle$ CRITICAL STEP Ensure that the brain is always submerged in HBBS during the whole dissection procedure.

9| Dissect out the hippocampi using a bottom lit stereomicroscope. Begin with the brain ventral side up and using Vannas spring scissors and straight forceps, remove the hemispheres from the diencephalon and brain stem. Remove the meninges from the medial aspect of each hemisphere and dissect the hippocampi.

$\triangle$ CRITICAL STEP Make sure to remove the meninges as completely as possible. Fibroblasts derived from the meninges are highly proliferative and can easily overgrow the neurons in a culture.

? TROUBLESHOOTING

10| Using the forceps, transfer the isolated hippocampi to a $15 \mathrm{ml}$ conical tube filled with prewarmed $\left(37^{\circ} \mathrm{C}\right) \mathrm{HBSS}$. After collecting all hippocampi, remove HBSS by decanting and replace with prewarmed trypsin-EDTA. Incubate at $37{ }^{\circ} \mathrm{C}$ for 10 min. ? TROUBLESHOOTING 


\section{BOX 2 | PREPARATION OF GLIAL SUPPORT CULTURES TIMING $\sim 14$ DAYS}

To establish a glial support culture, begin approximately 12 days before the nucleofection. All tools and solutions are as required for the dissection and preparation of the hippocampal neurons.

1. Warm HBSS and trypsin-EDTA to $37^{\circ} \mathrm{C}$ in a water bath.

2. Anesthetize a timed pregnant rat (E17) or mouse (E15.5) and kill the animal using an approved method.

3. In a laminar flow hood, sterilize the abdomen with Barrycidal or $70 \%$ ethanol. Using large forceps and scissors, make an incision on the mid-line through the skin starting at the pelvis and ending at the thorax, ensuring not to cut through the underlying muscle.

Separate the skin from the muscle and sterilize the abdomen with 70\% ethanol. Cut through the abdomen and open a large area to expose the uterus.

4. With the same forceps, take hold of the uterus between two embryos, lift and cut the uterine horn. Dissect out the entire uterus with the embryos and place in a sterile $10-\mathrm{cm}$ plastic tissue culture dish.

5. Carefully remove the embryos from the uterus. To do this, cut along the placenta of each embryo sack and allow the embryo to drop out. Cut the umbilical cord and place the embryo into a separate $10-\mathrm{cm}$ plastic dish filled with prewarmed HBSS.

6. Using smaller sterile forceps, place an embryo into a third, sterile 10-cm plastic dish without HBSS and decapitate with fine scissors.

Cut along the middle vein through the skin and skull and gently remove the skull to reveal the brain. Using a small spatula, remove the whole brain and place it into a small, 3 -cm sterile tissue culture dish filled with prewarmed HBSS.

7. Use Vannas spring scissors and straight forceps to remove the hemispheres from the diencephalon and brain stem of E15.5 mouse or E17 rat embryonic brains and subsequently remove the meninges from each isolated hemisphere. Two hemispheres are sufficient for each glial support culture. Place the hemispheres into a $15-\mathrm{ml}$ conical tube filled with prewarmed $\left(37^{\circ} \mathrm{C}\right) \mathrm{HBSS}$.

8. Decant the HBSS, add $5 \mathrm{ml}$ of prewarmed $\left(37^{\circ} \mathrm{C}\right)$ trypsin-EDTA and incubate for $10-20 \mathrm{~min}$ at $37^{\circ} \mathrm{C}$. Remove the trypsin-EDTA and add $5 \mathrm{~mL}$ of DMEM-HS. Triturate the hemispheres by gently pipetting up and down with a 10-ml pipette until no large pieces of tissue remain visible

(typically between 10 and 15 pipetting steps are required for the hemispheres to dissociate). Add the entire cell suspension to a pre-equilibrated $\left(37{ }^{\circ} \mathrm{C} ; 5 \% \mathrm{CO}_{2}\right)$ cell culture flask containing $15 \mathrm{ml}$ DMEM-HS.

9. To remove debris after the dissociation of the hemispheres, it is important to wash the glial culture $24 \mathrm{~h}$ after seeding. Wash two times with 10 $\mathrm{ml}$ of prewarmed PBS and add $15 \mathrm{~mL}$ of fresh, prewarmed DMEM-HS. Repeat this step 3-4 days later.

10. Seven days after preparation, passage the glial culture at a ratio of 1:3. Begin by removing the DMEM-HS and rinsing once with prewarmed PBS. Remove the PBS and add $3 \mathrm{ml}$ of trypsin-EDTA. Incubate at $37^{\circ} \mathrm{C}$ until all cells have detached from the surface and are in suspension. Add 2 volumes of DMEM-HS $(6 \mathrm{ml})$ and pipette up and down 10-15 times to dissociate any clumps of cells. Transfer 1 volume (3 $\mathrm{ml})$ of the cell suspension to a new tissue culture flask containing $12 \mathrm{~mL}$ of fresh prewarmed and equilibrated DMEM-HS.

- PAUSE POINT Excess glial cells can be transferred into freezing medium, frozen and stored at $-80^{\circ} \mathrm{C}$.

11. After 10-12 days, passage the glia a second time. Begin by equilibrating $5 \mathrm{ml}$ of DMEM-HS in the desired number of $6 \mathrm{~cm}$ cell culture dishes for $1 \mathrm{~h}$. Plate the glial cells in the pre-equilibrated dishes at a density of 20,000 cells per dish. Incubate for 2-3 days before replacing DMEM-HS with prewarmed $\left(37^{\circ} \mathrm{C}\right)$ NMEM-B27. After a minimum of $24 \mathrm{~h}$ in NMEM-B27, the glial cells are ready for the addition of the neuron-bearing coverslips.

For additional information and troubleshooting advice regarding the preparation of the glial support culture, see refs. 21 and 22.

11 After trypsinization, decant the solution and wash two times with HBSS. For each wash, fill the $15 \mathrm{ml}$ conical tube with HBSS and wait for the hippocampi to settle to the bottom (approximately $30 \mathrm{~s}$ ) and decant the HBSS. After the second wash, add 1.5-2 $\mathrm{ml}$ DMEM-HS $\left(37^{\circ} \mathrm{C}\right)$.

12| Triturate by gently pipetting the hippocampi up and down into a fire-polished Pasteur pipette until all of the tissue has dissociated (typically between 20 and 30 pipetting steps are required for the hippocampi to dissociate).

$\triangle$ CRITICAL STEP Do not triturate past this point, as excessive trituration will reduce cell viability.

? TROUBLESHOOTING

13| Triturate a second time for exactly 1 min with a fire-polished Pasteur pipette that has had its opening reduced to half of the original diameter. Note that between 250,000 and 300,000 neurons can be expected from each hippocampus.

$\triangle$ CRITICAL STEP The diameter of the fire-polished Pasteur pipette is critical. Too small a diameter reduces cell viability and too large a diameter results in incomplete dissociation of the hippocampi. Further details on the preparation of cultures of primary hippocampal neurons can be obtained from refs. 21,22.

? TROUBLESHOOTING

\section{Transfection}

14| If you are transfecting with the nucleofector device, follow option A. If you are transfecting using the 96-well shuttle system, follow option $B$.

(A) Transfection with the nucleofector device $\bigcirc$ TIMING $\sim 15$ min per each nucleofection

(i) Fill the desired number of culture dishes with B27-supplemented NMEM and preincubate the dishes at $37{ }^{\circ} \mathrm{C}$ and $5 \% \mathrm{CO}_{2}$ in an incubator until the medium has reached $37^{\circ} \mathrm{C}$ and the $\mathrm{pH}$ has equilibrated to 7.4 (may take up to $1 \mathrm{~h}$ ). 
(ii) Add $0.5 \mathrm{ml}$ of nucleofector supplement to $2.25 \mathrm{ml}$ of nucleofector solution (both stored at $4{ }^{\circ} \mathrm{C}$ ) and mix by pipetting up and down. Prewarm the mixture to room temperature (RT, approximately $22{ }^{\circ} \mathrm{C}$ ).

$\triangle$ CRITICAL STEP The nucleofector solution and nucleofector supplement can be stored at $4{ }^{\circ} \mathrm{C}$ for 6 months. Once supplemented, the solution can be stored at $4{ }^{\circ} \mathrm{C}$ for up to 3 months. Do not use the mixture beyond this period, as the transfection efficiency and cell viability are greatly reduced after this time.

(iii) Pipette $3 \mu \mathrm{g}$ of plasmid DNA (dissolved in $\mathrm{ddH}_{2} \mathrm{O}$ or TE buffer) into a sterile $1.5 \mathrm{ml}$ Eppendorf tube.

$\triangle$ CRITICAL STEP Ensure that the plasmid DNA preparation is very pure. Contamination with, for instance, bacterial endonucleases can result in reduced viability of neurons. The quality of the DNA preparation should also be assessed by measuring the $260 / 2800 \mathrm{D}$ ratio, which should be $\geq 1.8$ (and $<2.0$ ).

$\triangle$ CRITICAL STEP To ensure that your nucleofection worked properly, the pmaxGFP plasmid should always be included as a control in every experiment. If the transfection rate with the pmaxGFP plasmid is substantially lower than $70 \%$, you should refer to the Troubleshooting section.

? TROUBLESHOOTING

(iv) Take an aliquot of the neuronal cell suspension and determine the total amount of cells with a hemocytometer. For each nucleofection (one cuvette), between $2 \times 10^{5}$ and $6 \times 10^{6}$ cells will be required.

$\triangle$ CRITICAL STEP The number of cells used critically affects transfection efficiency and cell survival. ? TROUBLESHOOTING

(v) For each nucleofection, centrifuge an appropriate volume of neuronal cell suspension at $80 \mathrm{~g}$ and RT for 5 min. Carefully remove the supernatant and discard.

$\triangle$ CRITICAL STEP It is important to take off all of the supernatant, as residual medium interferes with the transfection efficiency.

(vi) Resuspend the pellet in $100 \mu \mathrm{l}$ of prewarmed (RT) nucleofector solution/supplement mixture.

$\triangle$ CRITICAL STEP All steps up to this point can be performed together for all subsequent nucleofections. However, make sure that you do not store the cells for more than $15 \mathrm{~min}$ in nucleofector solution/supplement mixture, as this will reduce both cell viability and transfection efficiency. All subsequent steps should be carried out sequentially for each nucleofection. Performing nucleofections in parallel can result in increased standby times, which may adversely affect the outcome of the transfection.

? TROUBLESHOOTING

(vii) Transfer the neuronal cell suspension into the $1.5 \mathrm{ml}$ Eppendorf tube containing plasmid DNA and mix by gently flicking the tube for approximately $20 \mathrm{~s}$.

$\triangle$ CRITICAL STEP It is recommended that the cells be resuspended in nucleofector solution/supplement mixture before the plasmid is added. If the plasmid is mixed with the nucleofector mixture before resuspending the cells, the cells tend to form aggregates, which can result in reduced cell viability.

$\triangle$ CRITICAL STEP Do not mix cells and plasmid DNA extensively with a pipette, as extensive pipetting damages the cells.

(viii) Transfer $100 \mu \mathrm{l}$ of the cell/DNA mixture into a dedicated nucleofection cuvette and place it into the cuvette holder of the nucleofector device.

$\triangle$ CRITICAL STEP Take care to avoid air bubbles, as they interfere with the flow of electrical currents during nucleofection and thus result in reduced transfection efficiencies.

(ix) Select the appropriate nucleofection program (e.g., number 0-003 for rat neurons and 0-005 for mouse neurons) and start the program.

I CAUTION The presence of foam in a cuvette after nucleofection indicates that numerous cells have died.

(x) Immediately after the nucleofection, carefully add $500 \mu \mathrm{l}$ of prewarmed $\left(37^{\circ} \mathrm{C}\right) \mathrm{DMEM}$-HS into the cuvette to minimize shearing forces when retrieving the cells from the cuvette.

(xi) Use a plastic pipette supplied by the manufacturer with the nucleofector kit to retrieve the cells from the cuvette, and seed them into an equilibrated $\left(37^{\circ} \mathrm{C} ; 5 \% \mathrm{CO}_{2}\right) 6 \mathrm{~cm}$ culture dish (either itself poly-L-lysine-coated or containing up to eight poly-L-lysine-coated coverslips) containing B27-supplemented NMEM and incubate at $37{ }^{\circ} \mathrm{C}$ and $5 \% \mathrm{CO}_{2}$. $\triangle$ CRITICAL STEP After nucleofection, retrieve the cells as fast as possible from the cuvette (without multiple resuspensions) and transfer them immediately into the equilibrated dish to ensure maximum viability. ? TROUBLESHOOTING

(xii) For each nucleofection, repeat Steps (vii)-(xi). Do not perform nucleofections in parallel, as increased standby times may adversely affect the outcome of the transfection.

(B) Nucleofection with the 96-well shuttle TIMING $\sim 60 \mathrm{~min}$

(i) Fill the required number of wells of a 96-well plate with $100 \mu \mathrm{L}$ NMEM-B27 or DMEM and preincubate the plate at $37{ }^{\circ} \mathrm{C}$ and $5 \% \mathrm{CO}_{2}$ in an incubator until the medium has reached $37^{\circ} \mathrm{C}$ and the pH has equilibrated to 7.4 (may take up to $1 \mathrm{~h}$ ).

(ii) Add $0.4 \mathrm{ml}$ of nucleofector supplement to $1.8 \mathrm{ml}$ of 96 -well nucleofector solution and mix by pipetting up and down. Prewarm the mixture to RT. 
$\triangle$ CRITICAL STEP The nucleofector solution and nucleofector supplement can be stored at $4{ }^{\circ} \mathrm{C}$ for 6 months. Once supplemented, the solution can be stored at $4{ }^{\circ} \mathrm{C}$ for up to 3 months. Do not use the mixture beyond this period, as the transfection efficiency and cell viability are greatly reduced after this time.

(iii) Pipette $0.5 \mu \mathrm{g}$ of plasmid DNA (dissolved in $\mathrm{ddH}_{2} \mathrm{O}$ or TE buffer) for each sample into the wells of a sterile 96 -well plate. (In cases where significantly fewer than 96 plasmids are to be used, pipette the plasmid DNA into individual Eppendorf tubes or PCR eight-tube strips.)

$\triangle$ CRITICAL STEP Ensure that the plasmid DNA preparation is very pure. Contamination with, for instance, bacterial endonucleases can result in reduced viability of neurons. The quality of the DNA preparation should also be assessed by measuring the $260 / 2800 \mathrm{D}$ ratio, which should be $\geq 1.8$ (and $<2.0$ ).

$\triangle$ CRITICAL STEP To ensure that your nucleofection worked properly, the pmaxGFP plasmid should always be included as a control in every experiment. If the transfection rate with the pmaxGFP plasmid is substantially lower than $70 \%$, you should refer to the Troubleshooting section. ? TROUBLESHOOTING

(iv) Take an aliquot of the neuronal cell suspension and determine the total amount of cells with a hemocytometer. For each nucleofection (one well of a 96-well plate), you require between $5 \times 10^{4}$ and $5 \times 10^{5}$ cells.

$\triangle$ CRITICAL STEP The number of cells used critically affects transfection efficiency and cell survival. ? TROUBLESHOOTING

(v) Centrifuge an appropriate volume of neuronal cell suspension at $80 \mathrm{~g}$ for $5 \mathrm{~min}$. Carefully remove the supernatant and discard.

$\triangle$ CRITICAL STEP It is important to take off all of the supernatant as residual medium interferes with the transfection efficiency.

(vi) Resuspend the pellet in prewarmed (RT) nucleofector solution/supplement mixture. The volume of nucleofector solution/ supplement mixture required depends on the number of conditions (i.e., wells) used in the experiment. Use $20 \mu \mathrm{l}$ of nucleofector mixture for each well.

$\triangle$ CRITICAL STEP Do not store the cells for more than $15 \mathrm{~min}$ in nucleofector solution/supplement mixture, as this will reduce both cell viability and transfection efficiency.

? TROUBLESHOOTING

(vii) Transfer the neuronal cell suspension into the wells of the 96-well plate or Eppendorf tube(s) containing the plasmid DNA and mix by gently swirling the plate or gently flicking the tube(s) for approximately $20 \mathrm{~s}$.

$\triangle$ CRITICAL STEP It is recommended that the cells be resuspended in nucleofector solution/supplement mixture before the plasmid is added. If the plasmid is mixed with the nucleofector mixture before resuspending the cells, the cells tend to form aggregates, which can result in reduced cell viability.

$\triangle$ CRITICAL STEP To speed up the procedure, it is recommended to use a multichannel pipette equipped with epT.I.P.S. pipette tips for the transfer of the neuronal cell suspension into the 96 -well plate.

$\triangle$ CRITICAL STEP Do not mix cells and plasmid DNA extensively with a pipette, as pipetting damages the cells.

(viii) Insert $2 \times 8$ module(s) into the corresponding frame of the nucleofector-compatible 96-well plate. Transfer $20 \mu \mathrm{l}$ of the cell-plasmid DNA-nucleofector mixture into the wells of the $2 \times 8$ module(s) and place the plate into the 96 -well shuttle nucleofector.

$\triangle$ CRITICAL STEP When pipetting the neuronal cell suspension into the wells of the $2 \times 8$ modules, make sure that the suspension is at the bottom of the well and take care to avoid air bubbles, as they interfere with the flow of the electrical currents during nucleofection and thus result in reduced transfection efficiencies.

$\triangle$ CRITICAL STEP To ensure proper assignment of nucleofection programs to the individual wells, make sure that well A1 is in the top-left position.

\section{? TROUBLESHOOTING}

(ix) Upload the desired parameter files from the predefined template parameter files (for instance, 96-CU-133 for high-viability and $96-E M-110$ for high-efficiency nucleofection of primary rat neurons) and start the nucleofection.

(x) Immediately after the nucleofection, carefully add $80 \mu \mathrm{l}$ of prewarmed $\left(37^{\circ} \mathrm{C}\right)$ DMEM-HS medium into each well and retrieve the neurons with a multichannel pipette with epT.I.P.S. pipette tips.

! CAUTION The presence of foam after a nucleofection means that numerous cells have died. ? TROUBLESHOOTING

(xi) Subsequently, seed the neurons at a density of 4.0-7.5 $\times 10^{4}$ cells per well into a sterile, poly-L-lysine-coated 96-well plate containing equilibrated B27-supplemented NMEM $\left(37{ }^{\circ} \mathrm{C} ; 5 \% \mathrm{CO}_{2}\right)$ and incubate at $37{ }^{\circ} \mathrm{C}$ and $5 \% \mathrm{CO}_{2}$. Alternatively, the cells can be seeded at a density of $10^{5}$ cells onto poly-L-lysine-coated glass coverslips in 12-well plates.

$\triangle$ CRITICAL STEP For embryonic neurons (e.g., E17 rat neurons), B27-supplemented NMEM should be used as culture medium, as these neurons do not grow well in DMEM. Postnatal day (P) 0 neurons, however, should be cultured in DMEM, as the survival rate of these neurons after nucleofection tends to be lower in NMEM. One day after the nucleofection, add Ara-C to the DMEM used to culture PO neurons at a final concentration of $5 \mu \mathrm{M}$. This inhibits the proliferation of glial 
PROTOCOL

cells, which are more abundant in preparations from postnatal brains. Add fresh Ara-C at a final concentration of $5 \mu \mathrm{M}$ every other day.

$\triangle$ CRITICAL STEP After nucleofection, retrieve the cells as fast as possible from the wells of the $2 \times 8$ modules and transfer them immediately into B27-supplemented NMEM to ensure maximal cell viability.

(xii) Four hours after plating, replace approximately two-thirds of the culture medium with fresh medium as required by the type of neuron.

\section{? TROUBLESHOOTING}

\section{TIMING}

Step 1: day 0, approximately 14 days (see also Box 2)

Steps 2-13: day 1, approximately 70 min

Steps 14 A/B (i): day 1, 5 min

Steps 14A (ii)-(xi): day 1 , approximately $10 \mathrm{~min}$ (per nucleofection)

Steps 14B (ii)-(xi): day 1, approximately $40 \mathrm{~min}$

Steps 14B (xii): day 1, approximately $15 \mathrm{~min}$

\section{Box 1:}

Coating of coverslips

Step 1: day 1, approximately $15 \mathrm{~min}$; day 2, approximately 75 min

Steps 2-3: day 2, approximately $8 \mathrm{~h}$

Steps 4-6: day 3, approximately 45 min (for one dish containing 6 coverslips; allow 5 min for every additional dish)

Step 7: day 4, approximately $2.5 \mathrm{~h}$

Step 8: day 5, approximately $70 \mathrm{~min}$

Coating of cell culture dishes or multi-well plates

Step 1: day 1, approximately $30 \mathrm{~min}$

Step 2: day 2, approximately $2.5 \mathrm{~h}$

Step 3: day 3, approximately $70 \mathrm{~min}$

\section{Box 2:}

Steps 1-8: day 1, approximately $40 \mathrm{~min}$

Steps 9: day 2, approximately $10 \mathrm{~min}$

Step 9 (repeat): day 5 or 6 , approximately $10 \mathrm{~min}$

Step 10: day 7, approximately 15 min

Step 11: day 10, 11 or 12 , approximately $30 \mathrm{~min}$; day $12,13,14$ or 15 , approximately $5 \mathrm{~min}$

\section{? TROUBLESHOOTING}

Trouble shooting advice can be found in Table 2 .

TABLE 2 | Troubleshooting table.

\begin{tabular}{|c|c|c|c|}
\hline Steps & Problem & Possible reasons & Solutions \\
\hline 9 & $\begin{array}{l}\text { Too many glial cells in the } \\
\text { neuronal culture }\end{array}$ & $\begin{array}{l}\text { Additional cortical tissue is being dissected } \\
\text { along with the hippocampi }\end{array}$ & $\begin{array}{l}\text { Make sure to remove only the hippocampus from } \\
\text { the hemisphere and not the adjacent attaching } \\
\text { cortical tissue. It is always better to err on the side } \\
\text { of caution and cut away some of the hippocampus } \\
\text { rather than risking contamination by adjoining } \\
\text { cortical tissue }\end{array}$ \\
\hline
\end{tabular}

10 Low cell survival rate Excessive trypsinization

10 and $14 \mathrm{~B}(\mathrm{xii})$
Numerous aggregates in culture; high rates of cell death

Mechanical damage to cells during dissociation
Limit incubation times in trypsin-EDTA solution to minimum required for dissociation of neurons; check success of trypsinization in hemocytometer

Insufficient trypsinization and/or dissociation of cells before nucleofection. Check success of trypsinization in hemocytometer Alternatively, replace culture medium with fresh medium $4 \mathrm{~h}$ after the nucleofection

Use appropriate pipettes and take care when mechanically dissociating the cells; check success of trituration in hemocytometer 
TABLE 2 | Troubleshooting table (continued).

\begin{tabular}{|c|c|c|}
\hline Problem & Possible reasons & Solutions \\
\hline $\begin{array}{l}13,14 \mathrm{~A}(\mathrm{xi}) \text { and } \\
14 \mathrm{~B}(\mathrm{x})\end{array}$ & $\begin{array}{l}\text { Neurons physically damaged during } \\
\text { pipetting steps }\end{array}$ & $\begin{array}{l}\text { Handle the neurons during the whole nucleofection } \\
\text { procedure with extreme care. Especially when } \\
\text { pipetting, be very gentle and use pipette tips with } \\
\text { large diameters to minimize shearing forces during } \\
\text { retrieval of neurons from cuvettes/wells }\end{array}$ \\
\hline
\end{tabular}

$14 \mathrm{~A}$ (iii) and 14B(iii) $14 \mathrm{~A}$ (iv) and
$14 \mathrm{~B}$ (iv)

$14 \mathrm{~A}$ (iv) and 14B(iv)

$14 \mathrm{~A}(\mathrm{vi})$ and $14 \mathrm{~B}(\mathrm{vi})$

$14 \mathrm{~A}$ (iii) and 14B(iii)

$14 \mathrm{~A}($ iii) and 14B(iii)

$14 \mathrm{~A}$ (iii) and 14B(iii)

$14 \mathrm{~A}$ (iii) and 14B(iii)

$14 \mathrm{~A}$ (iii) and 14B(iii)

$14 \mathrm{~A}$ (iv) and $14 \mathrm{~B}$ (iv)

14B(viii)

$14 \mathrm{~A}(\mathrm{xi})$ and $14 B(x)$
DNA plasmid preparation contaminated with endonucleases. Endonucleases are very toxi to neurons, and even relatively low amounts result in reduced viability of neurons

Too many neurons. The amount of neurons per cuvette/well is critical, as they aggregate when kept at too high densities

Too low a cell number

Prolonged exposure of neurons to nucleofector mixture

Low transfection rate

Amount of plasmid DNA used too low

Bad quality of plasmid DNA, for example, shows a 260/280 ratio of 1.8 (and $<2.0$ )

Evaporation of $\mathrm{H}_{2} \mathrm{O}$ from plasmid DNA solution leading to increased DNA concentration

Contamination of plasmid DNA aliquot or degradation of DNA owing to improper storage or contamination with DNases

Very small volumes of plasmid DNA preparation with very high concentrations are used

The amount of neurons per cuvette/well is critical for the transfection efficiency. Both too low and too high cell numbers impair the transfection

Reuse of nucleofection cuvettes or $2 \times 8$ nucleofection modules generally results in decreased transfection efficiencies

Neurons fail to develop If the failure to differentiate is not caused according to the classifica- by specific effects of the transfected DNA, tion of neuronal differentiation stages in culture 23 the levels of glial conditioning of the culture medium might be too low for the neurons to differentiate properly
Make sure that you use purification kits that remove bacterial endonucleases for purifying plasmid DNA, for example, the EndoFree Plasmid Maxi kit (Qiagen, 12362)

Use fewer than $6 \times 10^{6}$ neurons per cuvette for nucleofection with the nucleofector device and less than $5 \times 10^{5}$ per well with the 96 -well shuttle system

Use a minimum of $2 \times 10^{5}$ cells for nucleofection with the nucleofector device and at least $5 \times 10^{4}$ with the 96-well shuttle system

Retrieve neurons as fast as possible from the cuvette after nucleofection

The amount of plasmid DNA used per nucleofection should be between 1 and $5 \mu \mathrm{g}$ of plasmid DNA for the nucleofector device and approximately $0.5-3 \mu \mathrm{g}$ for the 96 -well shuttle nucleofector

Optimize DNA purification procedure. Sometimes, preparing a new batch of plasmid DNA solves the problem. Failing that, you might want to consider using $\mathrm{CsCl}$ gradients to purify DNA instead of plasmid purification kits

Spin all plasmid aliquots before use to bring condensate back into bulk volume; also pellets possible debris

Discard aliquot and use new one

Dilute plasmid before use in nucleofection procedure

Use between $2 \times 10^{5}$ and $6 \times 10^{6}$ neurons per cuvette in the nucleofector device and between $5 \times 10^{4}$ and $5 \times 10^{5}$ per well in the 96 -well shuttle nucleofector

Use fresh nucleofection cuvettes or $2 \times 8$ nucleofection modules for each experiment

Ensure that the glial co-cultures are covered with NMEM-B27 medium for at least $12 \mathrm{~h}$ before the addition of the neuron-bearing coverslips to allow sufficient glial conditioning of the medium to occur 
TABLE 2 | Troubleshooting table (continued).

\begin{tabular}{|c|c|c|c|}
\hline Steps & Problem & Possible reasons & Solutions \\
\hline 1 and Box 2 & & Glial co-culture is too dense & $\begin{array}{l}\text { Each } 6-\mathrm{cm} \text { dish should be plated with } \\
\text { approximately } 20,000 \text { glial cells. Too many glial } \\
\text { cells will compete with the neurons for the } \\
\text { nutrients in the medium and may thus lead to } \\
\text { the starvation of neurons. Make sure that the } \\
\text { number of glial cells per volume is counted } \\
\text { accurately with a hemacytometer before plating }\end{array}$ \\
\hline
\end{tabular}

Box 1

Although the above protocols have been optimized for use with freshly isolated E17 or P0 rat and E15.5 mouse primary hippocampal neurons, they can, in principle, be applied to any neuronal cell type, including neuronal cell lines and glia. It is also worth noting that in our experience the rat nucleofector kit can be used to transfect mouse neurons with comparable transfection efficiencies. For information on protocols for the nucleofection of other cell types, see the collection of protocols provided on the manufacturer's web page (http://www.amaxa.com/cell-database.html) as well as their collection of publications describing the use of the nucleofection technology (http://www.amaxa.com/citations.html).

The quality of neurons is an important factor for the success of any transfection. All transfection procedures and particularly nucleofection are stressful for neurons. Therefore, the neuronal preparation should be as good as possible to assure maximal survival rate after nucleofection. It is important to ensure optimal conditions during the isolation of the neurons, as well as before and after the nucleofection. In particular, the time required for the isolation of neurons and mechanical stress (e.g., shearing forces during pipetting) should be minimized, and shifts in temperature, $\mathrm{pH}$ and osmolarity should be avoided in cases where media are changed.

To ensure maximum cell viability and transfection efficiencies, perform the nucleofection procedures as rapidly as possible. Prolonged standby times of cells outside of NMEM reduce the cell viability.

\section{ANTICIPATED RESULTS}

In contrast to the comparatively low transfection rates obtained with $\mathrm{Ca}^{2+}$-phosphate/DNA-based methods (Fig. 1a), the transfection efficiency attainable with the nucleofector device typically ranges between $50 \%$ and $85 \%$ (Fig. 1b),

Figure 1 | Representative transfection efficiencies of primary neurons obtainable with different protocols. Fluorescence micrographs showing GFP expression in transfected neurons and corresponding phase-contrast images. Transfection was performed with (a) an optimized $\mathrm{Ca}^{2+}$-phosphate/DNA transfection protocol, (b) the nucleofector device and (c) the 96-well shuttle system. Images show 4 day in vitro (DIV) neurons (a) and 1 DIV neurons $(\mathbf{b}, \mathbf{c})$. The transfection efficiencies achieved in these experiments were approximately $75 \%$ for the nucleofector device, approximately $60 \%$ for the 96-well shuttle system and approximately $10 \%$ for the $\mathrm{Ca}^{2+}$-phosphate/DNA protocol. Scale bars, $20 \mu \mathrm{m}$.
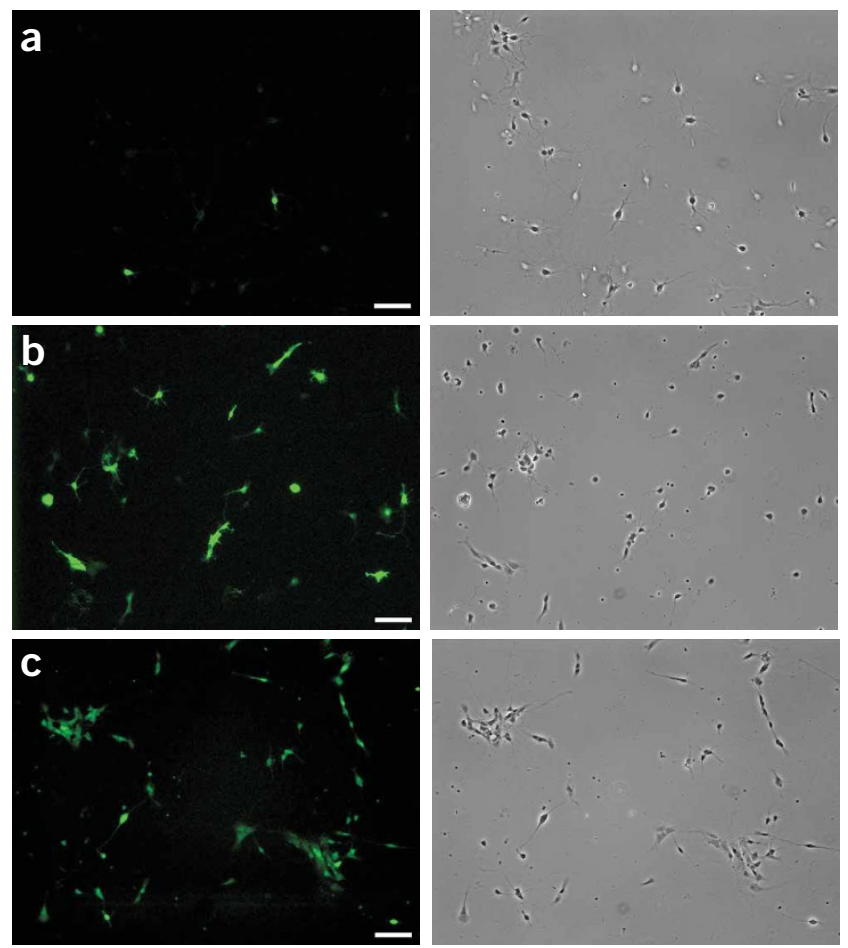

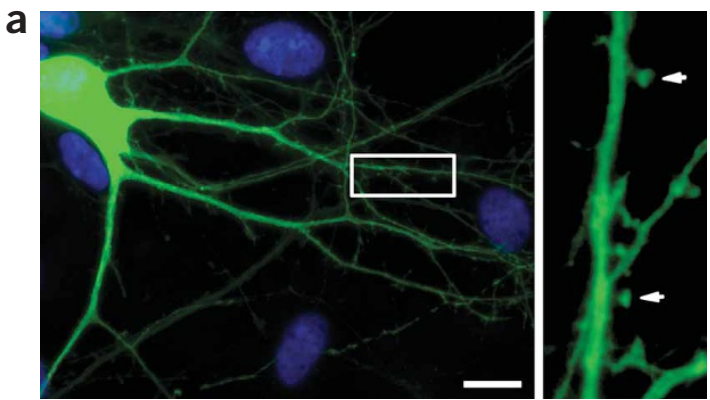

b

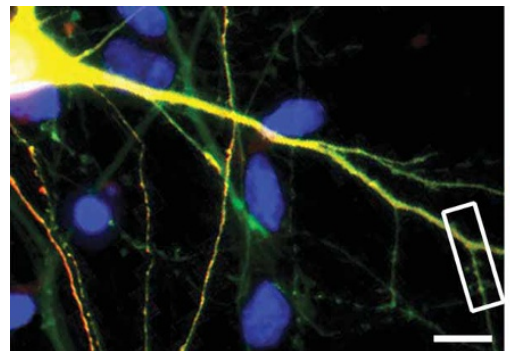

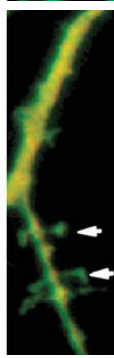

Figure 2 | Hippocampal neurons display normal differentiation and morphology after nucleofection with the 96-well shuttle system. Primary P0 rat hippocampal neurons were (a) nucleofected with a GFP (green) expression plasmid and (b) co-nucleofected with GFP and DsRed (red) expression plasmids and plated onto poly-L-lysine-coated glass coverslips. Nuclei were stained with DAPI (blue). Fluorescence microscopy images of co-nucleofected neurons show coexpression of the two plasmids in the same cell (b). Both single- and double-nucleofected neurons show the characteristic morphology of hippocampal neurons after 7 days in vitro (DIV), including axons and extended dendritic arbors. Insets (boxed areas in $\mathbf{a}$ and $\mathbf{b}$ ) show short stretches of dendrites at higher magnification. Arrows point to mushroomshaped dendritic spines characteristic of mature (stage 5) hippocampal neurons. Note: DAPI-stained nuclei surrounding the transfected neurons in a and $\mathbf{b}$ belong to glial cells. Scale bars, $10 \mu \mathrm{m}$.

depending also on the plasmid used. In our experience, after optimization this rate can increase to $95 \%$. Transfection efficiencies of $95 \%$ can, for example, be achieved with the pmaxGFP plasmid, which is included as a control with nucleofector kits. By contrast, in our experience, the transfection efficiencies obtainable with the 96 -well shuttle for primary neurons tend to be lower than that with the nucleofector device and generally range between $30 \%$ and $50 \%$ (Fig. 1c). This would preclude the use of this system when very high transfection rates are required. These figures have, however, to be seen in the context that the 96 -well shuttle has only been available since July 2006 and thus there has been little time to optimize protocols for the transfection of neurons for this device. It is therefore likely that transfection efficiencies will improve as more laboratories utilize this device and optimize the existing protocol described here. We have recently learned that Amaxa, the company that has developed the 96-well shuttle, has announced that they have succeeded in consistently achieving transfection efficiencies comparable to those obtained with the nucleofector device for a range of cell types. For further information, contact Amaxa directly (http://www.amaxa.com). It should, however, be noted that achieving high transfection efficiencies is not the most important advantage of the 96 -well shuttle. This system is primarily suited to large-scale parallel analyses of different plasmids or conditions.

The morphology of transfected cells is an important parameter used to assess any adverse effects of the transfection procedure on cell viability and fitness. This is particularly important with neurons, which are very susceptible to various forms of stress. In culture, differentiating neurons pass through five developmental stages to reach their mature morphology with an extended axon, a complex dendritic
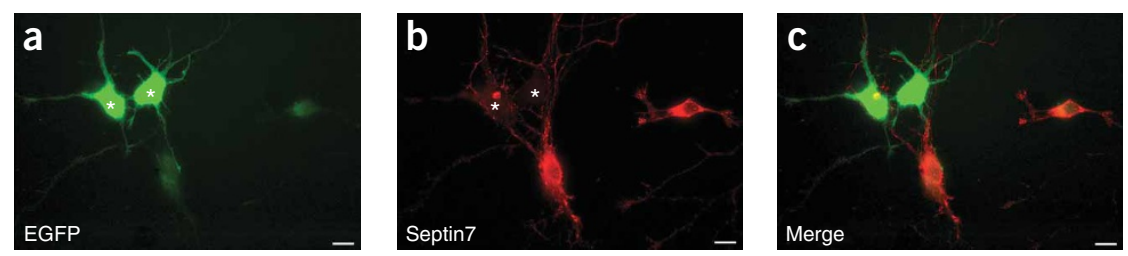

d

e
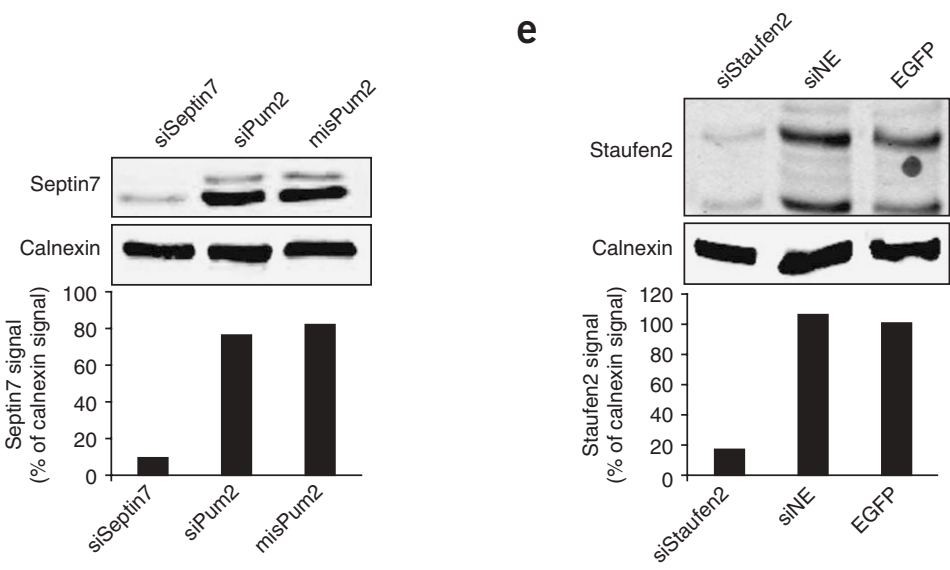

Figure 3 | Protein expression can be effectively downregulated by nucleofection of shRNA expression plasmids. Primary rat E17 hippocampal neurons were nucleofected with pSuperior shRNA vectors targeting either the Septin7 mRNA (a-d) or the Staufen2 mRNA (e) using the nucleofector device. (a-c) Fluorescence microscopy images of neurons stained with antibodies against endogenous Septin7 (red) reveal a reduction in protein levels in transfected neurons (as evidenced by expression of GFP (green); asterisks in $\mathbf{a}$ and $\mathbf{b}$ ) as compared to untransfected cells. (d,e) The extent of the knockdown was assessed by quantitative western blot analyses using fluorescently labeled antibodies detecting Septin7 (d) and Staufen2 (e) proteins and an LI-COR Odyssey Infrared Imaging system to measure fluorescence signals. In contrast to cells nucleofected with control plasmids (a pSuperior shRNA vector targeting the unrelated Pum2 protein (siPum2), a mismatch Pum2 siRNA vector (misPum2), an siRNA construct against an RNA not expressed in animal cells (siNE) and a plasmid expressing only EGFP), the expression levels of Septin7 and Staufen2, were significantly reduced in neurons nucleofected with RNAi constructs targeting the corresponding mRNAs. Note that neurons express two dominant isoforms of Staufen2 with molecular weights of 52 and $59 \mathrm{kDa}$, respectively, both of which are targeted and affected by the siRNA. Calnexin protein levels were used as loading controls. Western blot analyses were performed 3 days after nucleofection. Scale bars, $10 \mu \mathrm{m}$. 
tree and numerous synapses ${ }^{23}$. The nucleofection procedure does not affect the differentiation and morphology of neurons. They pass through the characteristic developmental stages and develop long axons, an extended dendritic arbor as well as the mushroom-shaped dendritic spines characteristic of mature hippocampal neurons (Fig. 2). Control pmaxGFP plasmid-transfected neurons (expressing only GFP) should be used as a reference to assess any putative phenotypes in neurons that have been transfected with other plasmids. Note that the cell in Figure $\mathbf{2 b}$ was co-transfected with two plasmids (pSyn-GFP and pDsRed), showing that co-transfections of two different plasmids are possible with the 96 -well shuttle system (and with the nucleofector device, data not shown).

The siRNA-mediated knockdown of genes is an effective and rapid method to assess the functions of specific genes in cell culture. It is, however, essential to validate the extent of the knockdown to be able to interpret the outcome of such experiments. This is usually achieved by quantitative western blot analysis of transfected cells and comparison of the levels of the targeted protein to the levels in untransfected or control-transfected cells. Such analyses rely on high transfection efficiencies to allow an optimal assessment of the extent of downregulation. The high transfection rates attainable by nucleofection allow performing quantitative western blot analyses and thus the assessment of the knockdown efficiencies. A representative experiment for assessing the efficiency of protein knockdown by RNAi is shown in Figure 3.

\begin{abstract}
ACKNOWLEDGMENTS We are grateful to Bernhard Götze, Ilse Höllinger, Daniela Karra, Paolo Macchi and Markus Zumbansen for helpful comments and critically reading the manuscript and for helpful discussions pertaining to this topic. Research in our laboratory is supported by the Schram-Stiftung, the SFB446 (University of Tübingen) and a start-up fund of the Medical University of Vienna (all to M.K.).
\end{abstract}

COMPETING INTERESTS STATEMENT The authors declare no competing financial interests.

Published online at http://www.natureprotocols.com

Reprints and permissions information is available online at http://npg.nature.com/ reprintsandpermissions

1. Giepmans, B.N., Adams, S.R., Ellisman, M.H. \& Tsien, R.Y. The fluorescent toolbox for assessing protein location and function. Science 312, 217-224 (2006).

2. Ward, T.H. \& Lippincott-Schwartz, J. The uses of green fluorescent protein in mammalian cells. Methods Biochem. Anal. 47, 305-337 (2006).

3. Dahm, R., Zeitelhofer, M., Goetze, B., Kiebler, M.A. \& Macchi, P. Visualising mRNA localisation and local protein translation in neurons. Methods Cell Biol. (in the press).

4. Hüttelmaier, S. et al. Spatial regulation of beta-actin translation by Src-dependent phosphorylation of ZBP1. Nature 438, 512-515 (2005).

5. Heim, N. et al. Improved calcium imaging in transgenic mice expressing a troponin C-based biosensor. Nat. Methods 4, 127-129 (2007).

6. Zeringue, H.C. \& Constantine-Paton, M. Post-transcriptional gene silencing in neurons. Curr. Opin. Neurobiol. 14, 654-659 (2004).

7. Schratt, G.M. et al. A brain-specific microRNA regulates dendritic spine development. Nature 439, 283-289 (2006).

8. Washbourne, P. \& McAllister, A.K. Techniques for gene transfer into neurons. Curr. Opin. Neurobiol. 12, 566-573 (2002).

9. Goetze, B., Grunewald, B., Baldassa, S. \& Kiebler, M. Chemically controlled formation of a DNA/calcium phosphate coprecipitate: application for transfection of mature hippocampal neurons. J. Neurobiol. 60, 517-525 (2004).

10. Goetze, B. \& Kiebler, M. Transfection of hippocampal neurons with plasmid DNA using calcium phosphate coprecipitation. in DNA Delivery/Gene Transfer Manual (eds. Friedmann, T. and Rossi, J.) 405-409 (Cold Spring Harbor Laboratory Press, Cold Spring Harbor, New York, USA, 2007).

11. Gresch, 0 . et al. New non-viral method for gene transfer into primary cells. Methods 33, 151-163 (2004).

12. Goetze, B. et al. The brain-specific double-stranded RNA-binding protein Staufen2 is required for dendritic spine morphogenesis. J. Cell Biol. 172, 221-231 (2006).

13. Li, Y. et al. Essential role of TRPC channels in the guidance of nerve growth cones by brain-derived neurotrophic factor. Nature 434, 894-898 (2005).

14. Gärtner, A., Collin, L. \& Lalli, G. Nucleofection of primary neurons. Methods Enzymol. 406, 374-388 (2006).

15. Leclere, P.G. et al. Effective gene delivery to adult neurons by a modified form of electroporation. J. Neurosci. Methods 142, 137-143 (2005).

16. Mueller-Hartmann, H. Method and circuit arrangement for treating biomaterial. US patent 2006/0094095 A1, filed 14 June 2005, and issued 4 May 2006.

17. Riemen, G. et al. Buffer solution for electroporation and a method comprising the use of the same. US patent 2005/0064596 A1, filed 23 April 2002, and issued 24 March 2005.

18. Iversen, N., Birkenes, B., Torsdalen, K. \& Djurovic, S. Electroporation by nucleofector is the best nonviral transfection technique in human endothelial and smooth muscle cells. Genet. Vaccines Ther. 3, 2 (2005).

19. Maasho, K., Marusina, A., Reynolds, N.M., Coligan, J.E. \& Borrego, F. Efficient gene transfer into the human natural killer cell line, NKL, using the Amaxa nucleofection system. J. Immunol. Methods 284, 133-140 (2004).

20. Muller-Hartmann, H. \& Habig, M. Container and device for generating electric fields in different chambers. W0 patent 2005/090547 A1, filed 15 March 2005, and issued 29 September 2005.

21. Kaech, S. \& Banker, G. Culturing hippocampal neurons. Nat. Protoc. 1, 2406-2415 (2006).

22. Goetze, B., Grunewald, B., Kiebler, M.A. \& Macchi, P. Coupling the iron-responsive element to GFP - an inducible system to study translation in a single living cell. Sci. STKE 2003, PL12 (2003).

23. Dotti, C.G., Sullivan, C.A. \& Banker, G.A. The establishment of polarity by hippocampal neurons in culture. J. Neurosci. 8, 1454-1468 (1988). 